\title{
Terminologia, cognição e
}

sociedade: análise dos processos de terminologização e de neologia que caracterizam as denominações da
área de Educação do Campo

\section{Terminology, cognition and society: analysis of the terminology and neology processes that characterize the denominations of the Field Education Area}

Resumo: A área-alvo deste trabalho é a Educação do Campo, expressão atribuída aos conceitos referentes ao ensino, à aprendizagem e à Educação nas regiões rurais, em que os principais atores são participantes de Movimentos Sociais do Campo. Serão discutidos aspectos da configuração semântico-pragmática e dos processos de terminologização, de neologia e de cognição que caracterizam a área-alvo, com ênfase em subprocessos relacionados à composição sintagmática combinada com isolamentos semânticos metafóricos e/ou metonímicos e/ou de especificação de domínio. 0 corpus é constituído por textos legais, de divulgação, pedagógicos e acadêmicos; sua periodicidade é de 2000 a 2010. São seguidas as Teorias Sociocognitiva e Comunicativa da Terminologia, valorizando aspectos cognitivos e comunicativos dos termos, sua contextualização linguística, discursiva, pragmática, sociocultural e histórica.

Palavras-Chave: Terminologia; Terminologização; Neologia; Educação do Campo; Cognição; Análise Conceitual "Centro Estadual de Educação Tecnológica Paula Souza - Ceeteps - São Paulo, SP, Brasil. Email:
fernanda.demai@gmail.com 
Abstract: The target area of this work is Field Education, an expression attributed to concepts related to education, learning and education in rural areas, where the main actors are participants in Social Field Movements. Aspects of the semantic-pragmatic configuration and terminologization, neology and cognition processes that characterize the target area will be discussed, with emphasis on subprocesses related to syntagmatic composition combined with metaphorical and / or metonymic semantic and /or domain specification isolation. The corpus is constituted by legal, dissemination, pedagogical and academic texts; its periodicity is from 2000 to 2010. The Sociocognitive and Communicative Theories of Terminology are followed, valuing cognitive and communicative aspects of the terms, their linguistic, discursive, pragmatic, sociocultural and historical contextualization.

Keywords: Terminology; Terminologization; Neology; Field Education; Cognition; Conceptual Analysis 


\section{Introdução}

Nesta seção introdutória, apresentaremos a área-alvo, a fundamentação teórica e os objetivos do trabalho.

Nossa área-alvo é a Educação do Campo, expressão atribuída aos conceitos referentes ao ensino, à aprendizagem e à educação nas regiões rurais, em que os principais atores são participantes de Movimentos Sociais do Campo. Nossa pesquisa abrange campos conceituais relativos aos princípios, metodologia, fins e ideais dessa modalidade de ensino, bem como a organização da estrutura de ensino e os atores sociais envolvidos.

Objetivamos discutir aspectos da configuração semântico-pragmática e dos processos de terminologização, de neologia e de cognição que caracterizam a área-alvo, com ênfase em subprocessos relacionados à composição sintagmática combinada com isolamentos semânticos metafóricos e/ou metonímicos e/ou de especificação de domínio, a partir da análise de textos fidedignos, exclusivamente escritos, em uma abordagem terminológica (com ênfase nos princípios das Teorias Sociocognitiva e Comunicativa da Terminologia).

Em relação à Teoria Comunicativa da Terminologia - TCT-, destacamos a valorização dos estudos semânticos, pragmáticos e morfossintáticos, sob um enfoque descritivista e não prescritivista e a concepção de termo como unidade de função comunicativa e discursiva (CABRÉ 1993, 1999). Dessa forma, os termos não sofrem intervenções ou modificações de cunho ortográfico, ou eliminação de sinônimos e variantes ou ainda em sua estrutura sintagmática: as unidades terminológicas são apresentadas e analisadas tal e qual foram extraídas dos contextos reais de utilização, dos textos do corpus.

Em relação à Teoria Sociocognitiva da Terminologia - TST -, destacamos os preceitos relacionados às funções comunicativa, cognitiva e discursiva dos termos, além da motivação terminológica (TEMMERMAN 2001, 2002).

Partiremos de uma abordagem do termo como um signo linguístico que representa um conhecimento especializado de uma área do saber humano, caracterizado pela integração e pela interação das "faces" significado e 
significante e pelos mesmos fenômenos morfossintáticos e semânticopragmáticos que formam e determinam as demais unidades da língua, como a variação, a sinonímia, a polissemia, a homonímia, a antonímia e os processos de neologia, como a fonológica, a sintática, a semântica. Concebe-se, dessa maneira, o signo linguístico e as linguagens de especialidade como itens culturais, determinados por valores sociopolíticos, históricos e culturais (BARbosa 2007; Cabré 1993, 1999; Demal 2014; Temmerman 2001, 2002).

Objetivamos demonstrar aspectos cognitivos característicos das unidades terminológicas, a fim de categorizar algumas das propriedades de termos sintagmáticos e de termos simples, especialmente em terminologias novas ou neológicas, cujos processos de lexicalização e de terminologização estão inacabados.

Para subsidiar o estudo dos processos de lexicalização, no âmbito da Terminologia, recorremos aos conceitos relacionados à terminologização, que, conforme Barbosa (2007), constitui-se no

processo que converte conceito em termo, la mise en terme, expressão esta comparável à la mise en lexème, do processo de lexemização de Pottier. Nesse sentido, terminologização refere-se à relação entre o nível conceptual e o metalinguístico [...]. No processo de passagem do conceptual para o terminológico, [há] a criação ex-nihilo, que terá graus diferentes de motivação, instauração de uma nova grandeza sígnica, numa combinatória inédita, no caso do processo fonológico e sintagmático [neológico]. O ponto de partida é o conceptual. [...] (BARBOSA 2007: 435-439).

A terminologização diz respeito à colocação de um conceito na forma linguística de um termo, com recurso aos processos de criação lexical disponíveis na língua geral (processos da neologia - fonológicos, morfossintáticos e sintagmáticos, semânticos ou por empréstimo de outras línguas), aplicados também às linguagens de especialidade.

Utilizaremos terminologização como arquiconceito e arquitermo, considerando que há a neutralização da oposição entre terminologização lato sensu (passagem do conceptual para o linguístico), terminologização stricto sensu (transformação de um vocábulo em termo) e a metaterminologização (instauração de um termo a partir de outro termo). Recorreremos também a Barbosa (2007) para justificar a adoção de terminologização como termo em função de classe que contém e representa conceitos correlacionados: 
A rigor, este processo - o da terminologização lato sensu - subjaz a todos os anteriormente apresentados, visto que, em estrutura profunda, o ponto de partida é sempre o nível conceptual (PAIS [...]). Diferem quanto aos percursos realizados pela grandeza-termo e quanto ao modo como é engendrada: fonológico, semântico, sintagmático ou alogenético (GUILBERT apud BARBOSA 2007: 438-439)

Assim, mencionaremos apenas "terminologização", como termo geral, como macroprocesso de transposição do conceito para o termo.

Em suma, a abordagem terminológica utilizada visa a estudar e a apreender aspectos de formas e modelos de pensamento, a partir da sistematização e estudo de termos técnicos e dos processos de terminologização e de neologia no âmbito de uma área do conhecimento.

Na próxima seção, apresentaremos e comentaremos os procedimentos metodológicos adotados, o corpus textual e os critérios para coleta e tratamento das unidades terminológicas.

\section{Procedimentos metodológicos, corpus textual e critérios para coleta de dados e de unidades terminológicas}

Trabalhamos com uma metodologia híbrida, de extração de palavras com a utilização de ferramenta informatizada, o programa WordSmith Tools (SCOTT, 2020), aliada à extração lexical manual e análise humana.

Utilizamos as três ferramentas básicas do WordSmith Tools: WordList (para elaboração de listas de termos); KeyWords (para extração de termoschave) e Concord (para extração de concordâncias ou expressões ou ainda termos sintagmáticos), e sistematizamos um corpus, ou seja, um conjunto organizado de textos para extração e análise lexical.

Nosso corpus é multitarefa: caracteriza-se pelas naturezas e pelas destinações pedagógica, acadêmica, de divulgação e de difusão de conceitos e de uma ideologia. Esse corpus é constituído por textos legais, textos de divulgação, textos e documentos pedagógicos, dissertações de mestrado e teses 
de doutorado; sua periodicidade é de 2000 a 2010, período fortemente marcado pela instauração, difusão e ressignificação de alguns dos mais representativos conceitos relativos à Educação do Campo.

Pesquisamos três instituições brasileiras para a coleta de dados terminológicos e conceituais: Centro Estadual de Educação Tecnológica Paula Souza (Ceeteps), Movimento dos Trabalhadores Rurais Sem Terra (MST) e Serviço Nacional de Aprendizagem Rural (Senar Nacional).

Com a utilização da ferramenta informatizada, extraímos listas de palavras, palavras-chave e concordâncias, ou seja, frases em que as expressões de destaque ocorrem.

Neste trabalho, apresentaremos a análise de um termo-chave, com seu respectivo campo ou rede conceitual, com a aplicação de critérios utilizados em Linguística e em Terminologia para validar o estatuto de conceito/termo fixo na sociedade, eliminando combinatórias eventuais, que não se repetem em outros textos e não chegam a configurar a terminologia (ou conjunto de termos da área).

Juntamente com esse recorte morfológico e sintagmático, utilizaremos um constructo, uma categoria organizadora e representativa dos termos em uma abordagem ligada ao pensamento, à apreensão e à representação mental e linguística do conhecimento: a "função cognitiva", característica de termos sintagmáticos e de termos simples, especialmente no contexto de um vocabulário neológico, seja pela temporalidade, seja pela falta de conhecimento do público em geral (e também de públicos ditos especializados) em relação às respectivas denominações e conceitos.

Para identificação e análise dos processos de lexicalização/terminologização, adotamos alguns critérios ou combinatória de critérios que avaliam aspectos da configuração morfossintática e semânticopragmática dos termos, a partir do estudo e sistematização de fatores linguísticos e também de fatores extralinguísticos.

A seguir, citamos o rol de critérios adotados para identificação de sintagmas terminológicos ou termos simples em diferentes estágios de lexicalização/terminologização, de acordo com as proposições teórico- 
metodológicas das autoras Alves (2007), BARBosA (2007), BARROS (2004) e DeMAI (2014, 2019):

- O sintagma/termo simples designa conceito em particular?

- O sintagma/termo simples tem forte e comprovada relação com a realidade extralinguística?

- O sintagma/termo simples constitui-se em empréstimo de outra área de conhecimento?

- O sintagma/termo simples possui sinônimos, quase-sinônimos, antônimos ou variantes?

- O sintagma/termo simples é combinado com isolamento semântico metafórico e/ou metonímico?

- O sintagma/termo simples é categorizável a partir de sua função na terminologia em estudo - cognitiva, expressiva, comunicativa, associativa, ideológico-persuasiva, estilística, discursiva, neológica, categorial, arquiconceitual?

- O sintagma/termo simples é categorizável a partir do estudo dos subprocessos de terminologização fonológico, morfossintáticosintagmático e semântico que compõem o macroprocesso da terminologização?

Os termos devem atender a todos, ou à maioria dos critérios elencados, para serem considerados no corpus.

$\mathrm{Na}$ próxima seção, proporemos a utilização de uma categoria organizadora de termos sintagmáticos e de termos simples, em terminologias neológicas, que subsidiará a análise conceptual-terminológica: a categoria função cognitiva.

\section{Proposição da utilização de uma categoria organizadora de termos sintagmáticos e de termos simples: a função cognitiva}

Com a análise dos termos da área de Educação do Campo, verificamos algumas funções dos compostos sintagmáticos, aplicáveis também a termos 
simples, próprias de sua organização no eixo sintagmático e decorrentes de suas relações no eixo paradigmático (DEmAl 2019).

Para os limites deste trabalho, nos ateremos à categoria função cognitiva, característica das unidades terminológicas em estudo, a ser apresentada a seguir.

\subsection{Função cognitiva como característica dos termos e do processo de terminologização da área de Educação do Campo}

A função cognitiva refere-se às formas de apreensão e de organização do conhecimento, da "realidade"/experiência do mundo físico-biológico e também do mundo sociocultural, coletivamente construído, sob diversas tensões ideológicas, sócio-históricas, políticas e culturais. Os termos são formas de manifestação da cognição humana por serem alternativas de organizar e de representar o conhecimento, com a utilização do aparato linguístico, em íntima relação com o nível conceptual.

No corpus da área de Educação do Campo, os termos (os sintagmáticos e os simples), associados à metáfora conceitual e à metonímia conceitual, por exemplo, são manifestações das formas de cognição direcionadas à terminologia.

Escolhemos neste trabalho adotar as denominações isolamento semântico para enfatizar os novos significados das composições sintagmáticas, que não são necessariamente a união do significado das partes. Os significados parciais podem possuir alguns semas ativados na composição (os quais são previsíveis, devido às virtualidades do sistema da língua), mas, na terminologia da Educação do Campo, a especificação de significados, própria das linguagens de especialidade, ao lado dos fatores extralinguísticos, ideológicos e pragmáticos, bem como o processo de lexicalização dos termos (em diferentes gradações), são determinantes do nível semântico.

O isolamento semântico dá origem a um "significado composicional", ou seja, um significado neológico, a partir de uma nova combinatória no eixo sintagmático (aqui, o neo tem origem, primeiramente, na combinatória inédita 
de itens lexicais no eixo horizontal da frase, que origina, em processo secundário ou complementar, outro significado, ocorrendo o que se denomina de neologia semântica em processo complementar). No caso de termos simples, um novo significado pode ser originado, em primeiro plano, pela neologia semântica. Essas e outras considerações sobre neologia são feitas especialmente a partir das proposições de Alves (2000, 2007), de Barbosa (1981) e de Guilbert (1973).

No processo de terminologização, ou seja, na transposição do conceito para o termo, não podemos deixar de observar os recursos cognitivos, de organização própria de uma determinada área de conhecimento, como a área de Educação do Campo.

Assim, por exemplo, os termos metonímicos e/ou metafóricos mística da luta, concepção de campo, memória da Educação do Campo, adolescência Sem Terra, juventude do campo, Sem Terra, entre muitos outros, manifestam as formas de categorização do conhecimento, com a utilização de referências de experiências anteriores, mesmo que de outro domínio. Em memória, a experiência de recordar de algo, de pensar em algo que ficou no passado, é transposta e recategorizada para o domínio do concreto: um relato, com a utilização de aparato linguístico, na modalidade oral ou na modalidade escrita. Mesmo em Sem Terra, a experiência de falta do bem gerou uma nova categoria, 'Sem Terra como sujeito ativo', com uma identidade não necessariamente disfórica, como a condição de falta.

A respeito das noções metalinguísticas encontradas nos textos de nosso corpus, que incluem conceitos de diacronia, de norma e de relação entre significado e significante, de ortografia, de dicionarização, da oposição linguística 'nome comum' e 'nome próprio', além das relações entre atuação político-social e a constituição de uma nova terminologia, citamos uma obra de autoria do MST (1999):

Alguns esclarecimentos sobre a grafia do nome Sem Terra: a condição (individual) de sem (a) terra, ou seja, a de trabalhador ou trabalhadora do campo que não possui sua terra de trabalho, é tão antiga quanto a existência da apropriação privada deste bem natural. No Brasil, a luta pela terra e, mais recentemente, a atuação do MST, acabaram criando na língua portuguesa o vocábulo sem-terra, com hífen, e com o uso do s na flexão do número ("os sem-terras"), indicando uma designação social para esta condição de ausência de propriedade ou da terra de

TradTerm, São Paulo, v.35, junho/2020, p. 5-24 www. revistas.usp.br/tradterm 
trabalho, e projetando, então, uma identidade coletiva. O MST nunca utilizou em seu nome nem o hífen, nem o $\mathrm{s}$, o que, historicamente, acabou produzindo um nome próprio, Sem Terra, que é também sinal de uma identidade construída com autonomia. 0 uso social do nome já alterou a norma referente à flexão de número, sendo hoje já consagrada a expressão os semterra. Quanto ao hífen, fica como distintivo da relação entre esta identidade coletiva de trabalhadores e trabalhadoras da terra e o Movimento que a transformou em nome próprio, e a projeta para além de si mesma. (MST 1999: 5)

Os termos possuem uma função cognitiva e favorecem os processos cognitivos, visto que, com a complexidade dos novos conceitos, em decorrência de novas tecnologias, novas ciências, novas técnicas e novas ideologias, as formas de expressão linguística mais simples, ou unitárias, acabam ficando mais restritas e não são suficientes para manifestar toda a especificidade, cada vez maior, das terminologias - a função cognitiva dos termos, como os termos em si, fazem parte de um contexto social e servem a atores e conjuntos de atores desse contexto.

Na próxima parte, apresentaremos a análise de um termo considerado chave para o estudo conceptual-terminológico a que nos propomos, com vistas a um aprofundamento dos aspectos relacionados à cognição, conceptualização e terminologização. 0 termo é: dinâmica do campo.

\subsection{Terminologização, cognição e representações do percurso conceptual-linguístico}

Apresentaremos a análise de um termo-chave, dinâmica do campo, conforme as considerações acerca dos processos de lexicalização/terminologização e em relação à função cognitiva que caracteriza o termo.

O termo dinâmica do campo designa um conceito em particular: 'procedimentos e eventos que caracterizam o funcionamento e as práticas de instituições e dos povos do campo'. O termo é utilizado nessa configuração semântico-lexical recorrente nos textos da área. O sintagma tem forte e comprovada relação com a realidade extralinguística: consta de textos de 
autoria de movimentos sociais do campo, de autores independentes, de textos acadêmicos.

Dinâmica do campo estabelece relações sinonímicas e de variação no universo do corpus em estudo, o que é comprovado pela coexistência do termo: dinâmica social do campo.

Dinâmica do campo é um termo sintagmático que traz aspectos cognitivos, à medida em que permite organizar e interpretar as realidades extralinguísticas. Esses aspectos cognitivos estão intimamente ligados a metáforas e a metonímias conceituais, conforme discutiremos a seguir.

\subsubsection{Metáforas e metonímias conceituais associadas à composição sintagmática e à especificação de domínio nos processos de cognição e de terminologização}

Dinâmica do campo é um termo sintagmático combinado com isolamento semântico metafórico e/ou metonímico.

Considerando aspectos metafóricos, a dinâmica é um estímulo para o desenvolvimento das ações do campo. Há transferência do significado concreto 'subárea da Mecânica que estuda o comportamento dos corpos em movimento' para o significado metafórico abstrato de 'estímulo para a evolução de algo', ou ainda 'movimento e mudança contínuos', que são algumas das principais tônicas dos Movimentos Sociais que protagonizam a Educação do Campo.

Em relação a aspectos metonímicos, a dinâmica é referente às pessoas que habitam e trabalham no campo e não no campo em si (como espaço físico, localização geográfica rural) - estabelece-se, dessa forma, a relação metonímica 'local ou espaço' representando ou "no lugar” das palavras que denominam os ocupantes ou moradores desses locais ou espaços.

As metáforas e as metonímias estão ligadas à cognição, em termos de apreensão da "realidade" e da expressão dessa realidade por vias linguísticas - e terminológicas, em casos de discursos especializados.

Para os limites deste trabalho, destacamos sinteticamente alguns pressupostos relacionados à metáfora e à metonímia conceitual (LAKOFF; JOHNSON 2003). 
A Teoria Cognitiva da Metáfora, proposta por George Lakoff e Mark Johnson em sua obra-marco Metaphors we live by, publicada originalmente em 1980, fundamenta muitos estudos sobre a natureza, as funções e as características de metáforas (e também de metonímias).

Com os estudos cognitivistas, a concepção de metáfora não é mais voltada ao subjetivismo ou a um objetivismo estreito, nem é pensada como aparato estético da linguagem. A metáfora é pensada como uma forma de conceptualizar e de interpretar a realidade, pois cria associações relativas ao homem e sua percepção de si, da sociedade e do "mundo natural" que o cerca.

Temmerman (2002) caracteriza, como bases da metaforização, o pensamento analógico ligado a um domínio-fonte e a um domínio-alvo e ressalta o papel das lexicalizações metafóricas e dos modelos cognitivos metafóricos na construção dos saberes e das terminologias de diversas áreas, como as Ciências Naturais ou Biológicas, dentre outras. (TEMMERMAN 2002: 212-213). As metáforas estão presentes na língua comum, nas terminologias e também nas manipulações estilísticas da linguagem.

Conforme Lakoff e Johnson (2003), pela sistemática da metáfora compreendemos aspectos de um conceito em termos de outro, ao passo que escondemos certos aspectos dos conceitos e enfocamos outros. (LAKOFF; JOHNSON 2003).

Nas terminologias, com a necessidade de mais e mais especificações, as metáforas aparecem ligadas às formações sintagmáticas como um recurso elucidativo, assim como também são relacionadas a termos simples, formados por uma única unidade vocabular.

Interessa-nos ressaltar os "isolamentos semânticos" decorrentes de usos metafóricos e de usos metonímicos, associados a isolamentos morfossintáticos. Dessa forma, abordaremos os significados composicionais, que são diferentes dos significados das partes.

A recorrência de isolamentos morfossintáticos e suas funções semânticas foram sistematizadas por Louis Guilbert (1965), quando de seu estudo da formação do vocabulário da aviação.

0 autor trata dos adjetivos recorrentes em composições sintagmáticas, ou sintagmas de integração, principalmente na transferência entre domínios de 
especialidade. Dessa forma, o isolamento morfossintático e a recorrência de um segundo elemento composicional carregam um componente semântico altamente motivado e com funções bem delimitadas.

$\mathrm{Na}$ obra de Guilbert (1965), podemos distinguir três funções para esses elementos recorrentes: adjetivos de transferência de domínio; adjetivos de especificação de domínio; adjetivos de transposição da língua geral para a linguagem de especialidade.

Interessa-nos, neste trabalho, identificar adjetivos de especificação de domínio ou estruturas morfossintáticas com essa função, a exemplo de sintagmas preposicionados com função adjetival (como é caso de do campo), altamente produtivo no corpus que embasa este estudo.

A recorrência de sintagmas preposicionados com função adjetival de especificação de domínio é uma das características do processo de terminologização referente à área de Educação do Campo. 0 termo-chave sob análise, dinâmica do campo, traz esse recurso (e respectivos resultados) da terminologização.

Dessa forma, não podemos analisar as características metafóricas e metonímicas do termo-chave dinâmica do campo de forma isolada, pois fazem parte de um padrão morfossintático e semântico-pragmático verificado no macroprocesso de terminologização da área de Educação do Campo.

$\mathrm{Na}$ função de especificação de um domínio, podemos citar os determinantes do Movimento, do Movimento Sem Terra, do MST, do campo, que determinam o primeiro elemento em várias composições sintagmáticas. Os elementos determinados cultura, mística, dinâmica e Base Social são muito abrangentes e utilizados em outros campos do saber. Com a determinação por esses sintagmas preposicionados, há uma especificação semântica, que faz parte da rede conceptual-terminológica da área em estudo, a exemplo de: mística do movimento, mística do Movimento Sem Terra, Base Social do MST, cultura do campo, dinâmica do campo, dinâmica social do campo.

A seguir, exemplificamos a existência "em rede", em campo conceitualterminológico do termo-chave em questão, dinâmica do campo, recorrendo ao mapa conceitual hierárquico da Categoria temática “3. Organização estrutural 
da Educação do Campo", mais especificamente da classe conceitual "3.1 Estruturação física e organizacional da Educação do Campo":

\section{Organização estrutural da EC}

3.1 Estruturação física e organizacional da Educação do campo

3.1.1. acampamento do MST (pref)

3.1.2. área de assentamento de reforma agrária (pref)

3.1.3. áreas de assentamento (var)

3.1.4. áreas de reforma agrária (pref)

3.1.5. assentamento do Movimento Sem Terra ( $\sin )$

3.1.6. assentamento do MST (pref)

3.1.7. campo da agricultura camponesa (pref)

3.1.8. campo da educação do campo (pref)

3.1.9. campo do agronegócio (ant)

3.1.10. coordenação da Educação do Campo (pref)

3.1.11. coordenação do assentamento (pref)

3.1.12. dinâmica do campo (pref)

3.1.13. dinâmica social do campo (sin)

3.1.14. documentos do MST (pref)

3.1.15. farmácia comunitária do acampamento (pref)

3.1.16. funcionamento da cooperativa-escola (pref)

3.1.17. lona preta (pref)

3.1.18. núcleo de agricultores familiares não-assentados (sin)

3.1.19. núcleo de agricultores não-assentados (pref)

3.1.20. núcleo de reforma agrária (pref)

3.1.21. organicidade do Movimento (sin)

3.1.22. organicidade do MST (pref)

3.1.23. organização do assentamento (pref)

3.1.24. organização do coletivo do assentamento (var)

3.1.25. organização do MST (pref)

3.1.26. pré-assentamento (pref)

Figura 1 - Mapa conceitual hierárquico da Categoria temática "3. Organização estrutural da Educação do Campo - Classe conceitual "3.1 Estruturação física e organizacional da Educação do Campo". Extraído de: Demal 2014: 141-142

O mapa conceitual hierárquico é um esquema que sistematiza e hierarquiza os conceitos de uma área ou campo do saber, representando a relação de pertença dos itens subordinados a classes mais abrangentes, os superordenados. A classe contém exatamente uma significação mínima, um núcleo sêmico em comum a todos os elementos subordinados. Esses elementos subordinados trazem, a mais, semas específicos, que os torna indivíduos, diferenciados, “únicos”, mas pertencentes a uma classe.

O mapa conceitual hierárquico possui função cognitiva à medida que se constitui em um instrumento de organização e de representação do pensamento, por vias linguísticas, além da extrema relevância que possui no 
engendramento do processo de categorização do pensamento, um processo primordialmente cognitivo.

Apresentamos também o mesmo mapa em formato de mapa conceitual relacional:

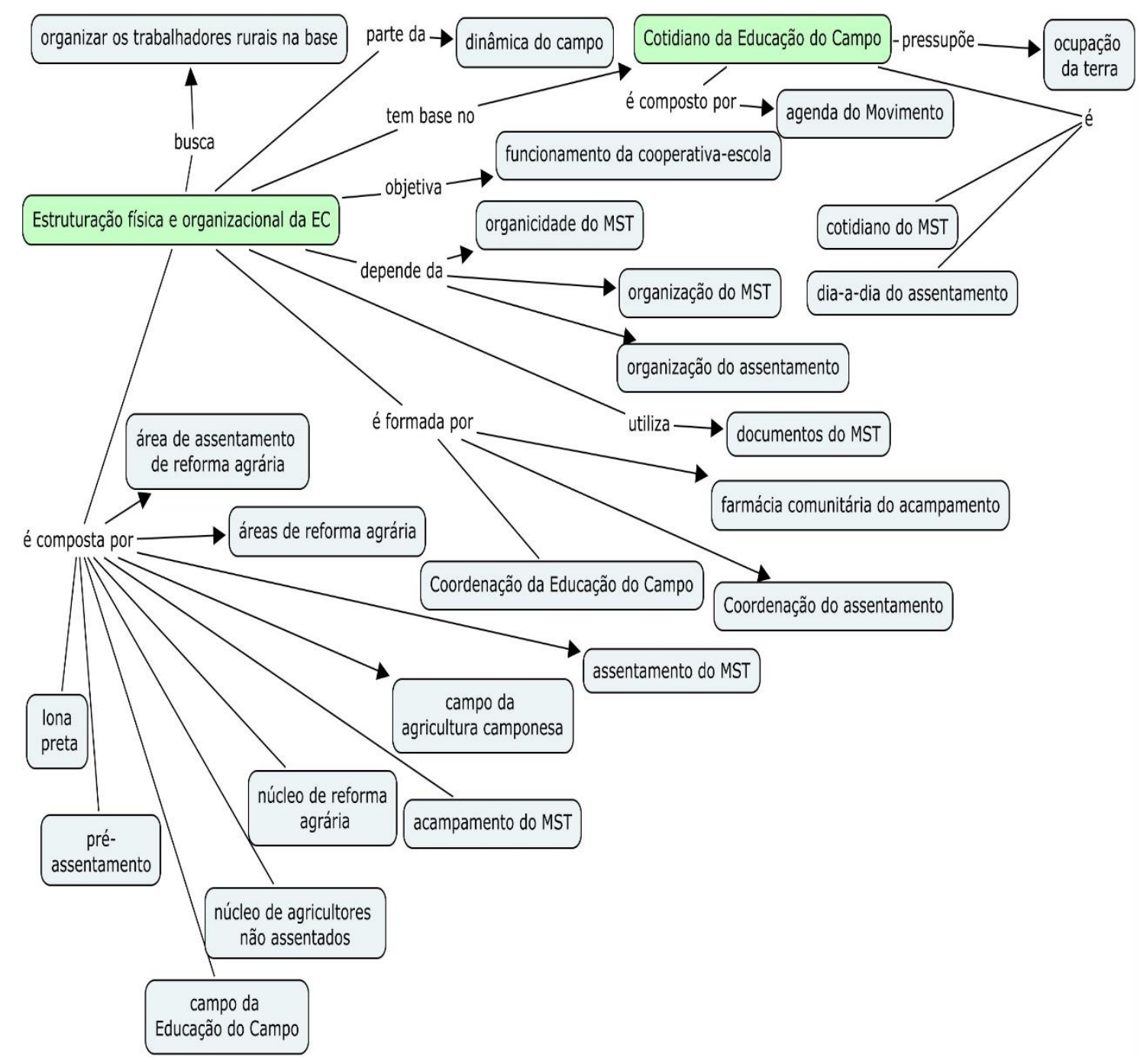

Figura 2 - Mapa conceitual relacional "Estruturação física e cotidiano da Educação do Campo". Extraído de: DEMAl, 2014: 155.

O mapa conceitual relacional caracteriza-se por uma estruturação não hierárquica, em que muitas relações entre os conceitos podem ser facilmente expressas por vias linguísticas e com mais recursos visuais em relação às potencialidades de um mapa conceitual hierárquico, considerando a utilização de formas geométricas diversas, setas, cores. 0 mapa conceitual relacional também possui função cognitiva de representação e apreensão do conhecimento e do pensamento, com vantagens de ser muito mais "livre" em 
sua configuração e muito mais compreensível e manipulável, principalmente para o público leigo, que desconhece as classes ou categorias principais e que, por conseguinte, encontra dificuldades em buscar um conceito em um mapa estritamente hierárquico. Os dois tipos de representação, hierárquica e não hierárquica, são fundamentais para o trabalho terminológico e de análise conceitual e não se excluem.

Para a elaboração do mapa conceitual relacional que consta da Figura 2, foi utilizado o programa CMap Tools, cuja última versão disponível é a 6.04 (INSTITUTE FOR HUMAN AND MACHINE COGNITION - IHMC, 2020).

A partir das representações visuais em forma de mapas, (tanto do mapa conceitual hierárquico, como do mapa conceitual relacional -não hierárquico), constata-se que o termo-chave, dinâmica do campo (assim como todos os outros), configura-se em uma rede conceitual, que dispõe de vários processos de terminologização (ou a "colocação do conceito em forma de item linguístico"), como o morfossintático, caracterizado por isolamento semântico metafórico e metonímico, especialmente na função adjetival de especificação de domínio - para um vocabulário especializado neológico, esse recurso de repetição, de "autoafirmação" ideológica por vias linguísticas é frequente e eficiente - logo, a repetição, em muitos termos, dos sintagmas preposicionados em função adjetival e de adjetivos simples "do campo", "do MST [=Movimento dos Trabalhadores Rurais Sem Terra]", "da Reforma Agrária”, "da terra”, "do assentamento", “do acampamento", "da EC [=da Educação do Campo]" e "camponês" é intencional, por parte dos ideólogos da área que, paulatinamente, constroem o universo discursivo que representa os conceitos pertinentes aos seus princípios e práticas; a repetição, a metaforização, a metonimização, a composição sintagmática com elementos já conhecidos, atribuindo novo significado, os significados composicionais, recursos cognitivos de apreensão, representação e interpretação do conhecimento, altamente relevantes e utilizados na terminologia em estudo.

Consideramos interessante comentar que a recorrência de formações sintagmáticas e de adjetivos, com fins de especificação semântica, é um recurso de engendramento conceptual-terminológico verificado em quase metade de nosso corpus, o que, sem dúvida, é muito significativo. 
Com os autores citados, referências em neologia, pudemos observar que a riqueza do recurso da determinação em termos compostos vai além do eixo sintagmático, fazendo parte de todo um complexo processo semântico - e também pragmático e ideológico - que representa a criação e a criatividade lexical no âmbito das sociedades e das culturas.

\section{Considerações finais}

A Educação do Campo é uma área cuja terminologia está em constituição, assim como a difusão de seus conhecimentos na sociedade brasileira, pois os conceitos estão restritos aos meios de produção acadêmica e aos movimentos sociais do campo - os conceitos são difundidos por meios de comunicação de uma forma "marcada negativamente", preconceituosa - logo, os verdadeiros valores da Educação do Campo e seus respectivos termos ainda são "novidade" para o público em geral.

Utilizamos algumas abordagens teórico-metodológicas da Teoria Comunicativa da Terminologia e da Teoria Sociocognitiva da Terminologia, principalmente no que diz respeito à valorização dos estudos semânticos, pragmáticos e morfossintáticos, sob um enfoque descritivista e não prescritivista. Ao analisar os processos de sintagmação, reconhecemos e estudamos a ligação entre morfologia, sintaxe e semântica, a partir de contextos reais de comunicação da área-tema.

A pesquisa é descritivista: não se propõe a modificar, padronizar ou rechaçar as unidades terminológicas encontradas em discurso manifestado e abonadas pelos especialistas e atores sócio-históricos do contexto.

Temos a concepção de que termo é uma unidade de função comunicativa, discursiva e cognitiva; os termos são extraídos de textos reais, que disciplinam e constroem a área discursivamente, por intermédio de sua terminologia.

$\mathrm{Na}$ pesquisa, buscamos valorizar os termos como unidades de conhecimento, a partir de modelos mentais e de formas de pensar, de apreender e de sistematizar a realidade, a exemplo de metáforas e metonímias 
conceituais e processos de conceptualização, terminologização e sintagmação - enfim, de cognição.

As unidades terminológicas (termos) manifestadas em discursos reais provêm de um percurso mental que, juntamente com as condicionantes sociais, coletivas e ideológicas, resultam na estruturação linguística, ou seja: a lexicalização e a terminologização, processos esses que são motivados, históricos e passíveis de análises tanto sincrônicas como diacrônicas, tanto históricas, sociológicas, políticas, como linguísticas.

A ideologia nas relações entre denominação e significação é presente em todos os campos do saber, em todas as culturas, em toda manifestação humana - a Educação do Campo é somente um exemplo dessa propagação de valores ideológicos e axiológicos.

Cremos que a Terminologia e a Linguística não podem adotar um tratamento superficial em relação a aspectos ideológicos, visto que são ciências sociais e considerando que esses valores ideológicos interferem na constituição linguístico-terminológica e na semântica de termos e de palavras. A busca por um patamar cognitivo-ideológico de cada área estudada não seria, assim, uma questão de escolha, mas uma obrigação científica.

Defendemos que análises linguístico-terminológicas não devem se abster de levar em consideração as principais facetas ideológicas da configuração das palavras e dos termos pertinentes a uma língua e a uma cultura, pois a língua é um instrumento social, para fins sociais.

\section{Referências}

ALVES, I. M. Um estudo sobre a neologia lexical: os microssistemas prefixais do português contemporâneo. 2000. 380f. Tese (Livre-Docência - Letras Clássicas e Vernáculas) - Faculdade de Filosofia, Letras e Ciências Humanas, Universidade de São Paulo, São Paulo. . Neologismo: criação lexical. 3. ed. São Paulo: Ática, 2007.

BARBosa, M. A. Léxico, produção e criatividade: processos do neologismo. São Paulo: Global, 1981. 
- Etno-terminologia e terminologia aplicada: objeto de estudo, campo de aplicação. In: Isquerdo, A. N.; ALVES, I. M. (Org.). As Ciências do léxico: lexicologia, lexicografia, terminologia, v. 3. Campo Grande: Ed. UFMS; São Paulo: Humanitas, 2007: 433-445.

BarRos, L. A. Curso básico de Terminologia. São Paulo: Editora da Universidade de São Paulo, 2004.

CABRÉ, M. T. La terminología: teoría, metodología, aplicaciones. Barcelona: Editorial Antártida/Empúries, 1993.

. La terminología: representación y comunicación - elementos para una teoría de base comunicativa y otros artículos. Barcelona: Institut Universitari de Lingüística aplicada/Universitat Pompeu Fabra, 1999.

Demal, F. M. Processos de terminologização: descrição e análise da neologia da área de Educação do Campo. 2014. 417 f. Tese (Doutorado em Letras: Filologia e Língua Portuguesa) - Faculdade de Filosofia, Letras e Ciências Humanas, Universidade de São Paulo, São Paulo, 2014. Disponível em: <www.teses.usp.br/teses/disponiveis/8/8142/tde.../2014_FernandaM elloDemai_VOrig.pdf> Acesso em: 19 maio 2020.

Análise da lexicalização e das funções das unidades terminológicas da área de Currículo Escolar em Educação Profissional Técnica de Nível Médio organizado por competências. Estudos linguísticos, São, v. 48, , n. 1, 2019, p. 164-182. Disponível em: <https://revistas.gel.org.br/estudos-linguisticos/article/view/2146>. Acesso em: 19 maio 2019.

GUILBERT, L. La formation du vocabulaire de l'aviation. Paris: Librairie Larousse, 1965.

.Théorie du néologisme. In: Cahiers de l'Association internationale des études francaises, n. 25, 1973, p. 9-29. Disponível em: <http: / /www.persee.fr/web/revues/home/prescript/article/caief_05 71-5865_1973_num_25_1_1020>. Acesso em: 19 maio 2019.

Institute For Human And Machine Cognition - IHMC. Cmap Tools. Software de construção de mapas conceituais/modelos mentais. Knowledge Modeling Kit - Latest version 6.04. 2020. Disponível em: <http://cmap.ihmc.us/>. Acesso em: 10 abr. 2020.

LaKoff, G.; Johnson, M. Metaphors we live by. Chicago; London: University of Chicago Press, 2003 [1980].

Movimento Dos Trabalhadores Rurais Sem Terra - MST . Como fazemos a escola de educação fundamental? São Paulo: Iterra, 1999.. 
ScoTT, M. WordSmith Tools version 8, Stroud: Lexical Analysis Software. Tools: Wordlist, Keywords e Concord. 2020. [latest version]. Disponível em: <http://www.lexically.net/publications/citing_wordsmith.htm>. Acesso em: 10 abr. 2020.

Temmerman, R. Sociocognitive Terminology Theory. In: Cabré, M. T.; Feliu, J. (ed.). Terminología y cognición II. Simposio Internacional de Verano de Terminología (13-16 de julio de 1999). Barcelona: Institut Universitari de Lingüística Aplicada. Universitat Pompeu Fabra, 2001.

. Metaphorical models and the translator' s approach to scientific texts. Antverpiensia New Series - Themes in Translation Studies. Antwerp, n. 1, 2002.. Disponível em: <https://lanstts.uantwerpen.be/index.php/LANS-TTS/index>. Acesso em: 6 out. 2018.

Recebido em: 22/05/2019

Aceito em: 09/04/2020

Publicado em junho de 2020 